\title{
Utilization of the zero unitarization method for the building of a ranking for diagnostic marine engine parameters
}

Changing some of the parameters of the engine structure affects the emission of harmful components in the exhaust gases This primarily concerns damage in the cargo exchange system as well as in the fuel system and engine boost system. Changes in emissions of harmful compounds are often ambiguous, depending largely on the parameters that shape the combustion process. An additional problem is that often simple but undesired interactions occur with the interaction of these parameters. It is therefore possible to speak of different diagnostic parameters' sensitivity to the same extractions from the engine structure, but implemented in other load states. In cases where the set of parameters is numerous and the values of these parameters are similar, there is a real problem with their proper classification, often based on the discretion of the researcher. In the paper the authors propose a methodology for classification of acquired diagnostic parameters. In previous papers [4, 5], Hellwig's method of information capacity index was proposed as a measure of diagnostic parameter sensitivity. This method can be used to build a diagnostic parameter ranking that divides the set of diagnostic variables into stimulators, destimulators and nominators. This normalization of the set seems to be helpful in making a diagnostic decision not influenced by the discretion of the researcher. The zero unitary method can also be helpful in creating diagnostic tests.

Key words: diagnostic, theory of experiments, marine diesel engine, exhaust gas toxicity, multi-equation models

\section{Introduction}

Transient states are particular states of the combustion engine operation. It should be explained by stating that the transient states disrupt the thermodynamic equilibrium of the cylinder which is present during the stationary loads. It disrupts the flow of the combustion process through momentary changes of the stream of fresh load delivered to the cylinder, as well as the amount of delivered fuel. As such, the ratio of fuel-air is temporarily changed, resulting in the shift of the combustion air factor, which leads to the increased emission of combustion products created through the local deficiency of oxygen. Further consequence of the increased amount of carbon oxide $\mathrm{CO}$ and unburned hydrocarbons $\mathrm{HC}$ is the decrease in the combustion temperature, which dictates the lowered emission of nitric oxide $\mathrm{NO}_{\mathrm{x}}$.

As such, the deciding factor for the value of toxic compound emissions originating from the transient states is, above all else, the value of excitations which trigger these states. It is not, however, the only factor. Another factor shaping the value of toxic compound emissions originating from the transient states which should be taken into consideration is the technical state of the engine. This state, described using the structure parameters, undergoes constant changes throughout the operation of the engine, which changes are responsible for the wear process. This intensifies the changes in the development of the toxic compounds during the transient states because the processes, while momentary, are dynamic enough to result in the CI concentrations by far exceed the values of the stationary states. Thus it should be expected that the engine with its structural parameters changed through wear will be more sensitive to the influence of transient states and determining its technical state will be easier. At the same time, a problem of unique identification arises, not for the diagnostic parameters, but for their sensitivity. It is especially vital in the cases with large quantities of the tested material as well as with large variations in the operation of the transient states. The aforementioned sensitivity of the diagnostic parameter can be defined as an information capacity and used further to specify the parameters that best describe the given phenomenon $[1,2]$.

One of the basic parameters deciding the correctness of the course of combustion inside of the CI engines is the angle of fuel injection. Even a small deviation of this angle results in substantial changes in the main indices of the engine operation, including the indices of exhaust emission. In the case of classic engine design, the "spontaneous" change in the angle of advance of fuel injection is unlikely. On the other hand, in the modern engine design, where the majority of the regulatory parameters is electronically controlled, it is possible for a situation to occur where it results in damage being done to the control system and the change of the angle of advance of fuel injection.

This paper is a continuation of the problem published by the authors in $[4,5]$. Currently, the authors concentrate on defining and researching of the information capacity of the diagnostic parameter, which, as mentioned before, are the indices and characteristics of the exhaust gas compound emissions.

\section{Research on capacity indicators of toxic com- pounds concentrations during dynamic processes}

The tests were conducted on an engine fuel supply system (angle of advance of fuel injection) of a single cylinder test engine 1-SB, installed inside of the Laboratory of Marine Plant Exploitation of Polish Maritime Academy [3]. The experimental material was gathered using a developed trivalent complete plan. The realization of separate measurement systems (measurement points) of the aforementioned plan of experiment was achieved by using a programmable controller which allowed for getting a high repeatability of the dynamic processes. The duration of the dynamic process was assumed as the period between the introduction of the new injection system setting and the recurring stabilization of the output quantities. This time was chosen through experimentation and it amounts to about $106 \mathrm{~s}$. 
In order to identify the impact of the technical state of the fuel system on the power parameters of the engine during the dynamic processes, determined were ranges of input quantities (preset parameters) and output quantities (observed parameters).

To the needs of this paper, the size of the input quantities $X$ was limited to three elements, i.e.: $x_{1}$ - engine speed $\mathrm{n}[\mathrm{r} / \mathrm{min}] ; \mathrm{x}_{2}-$ engine torque $\mathrm{T}_{\mathrm{tq}}[\mathrm{N} \cdot \mathrm{m}] ; \mathrm{x}_{3}-$ angle of advance of fuel injection $\alpha_{w w}\left[{ }^{\circ} \mathrm{CA}\right]$. The research was conducted according to the adopted complete plan for the three engine speed values, i.e.: $850,950,1100 \mathrm{r} / \mathrm{min}$. For each of the engine speed values the torque $\mathrm{T}_{\mathrm{tq}}$ was increased, resulting in transient states for the following loads: 10, 20, 30, $50,70 \mathrm{~N} \cdot \mathrm{m}$. In the case of the rotational speed of $850 \mathrm{r} / \mathrm{min}$, out of concern for overworking the engine, loads of 50 and $70 \mathrm{Nm}$ were omitted. Similarly treated was the speed of 950 $\mathrm{r} / \mathrm{min}$ with the load of $70 \mathrm{Nm}$. The angle of advancement of fuel injection was changed by $\pm 5^{\circ} \mathrm{CA}$, resulting in three values, i.e.: nominal value $-\mathrm{N}$, accelerated angle $-\mathrm{W}$, delayed angle $-\mathrm{P}$. Using this method resulted in 36 repeated transient states. The model scheme of the functional test subject was represented in Fig. 1.

Similarly treated was the range of output values $\mathrm{Y}$, the number of its elements reduced to only the basic toxic compounds in the exhaust manifold: $\mathrm{y}_{1}-$ condensation of carbon dioxide in the exhaust manifold $\mathrm{C}_{\mathrm{CO}}$ [ppm]; $\mathrm{y}_{2}-$ condensation of hydrocarbons in the exhaust manifold $\mathrm{C}_{\mathrm{HC}(\mathrm{k})}[\mathrm{ppm}] ; \mathrm{y}_{3}-$ condensation of nitric oxides in the exhaust manifold $\mathrm{C}_{\mathrm{NOx}}[\mathrm{ppm}] ; \mathrm{y}_{4}$ - temperature of the exhaust gases $\mathrm{t}_{\mathrm{sp}}\left[{ }^{\circ} \mathrm{C}\right] ; \mathrm{y}_{5}-$ excess air number $\lambda$.

As mentioned before, the observed data gathered during the active experiment, as well as the multiequation model [3-6] based off of it, were used for the detailed analysis of the dynamic processes.

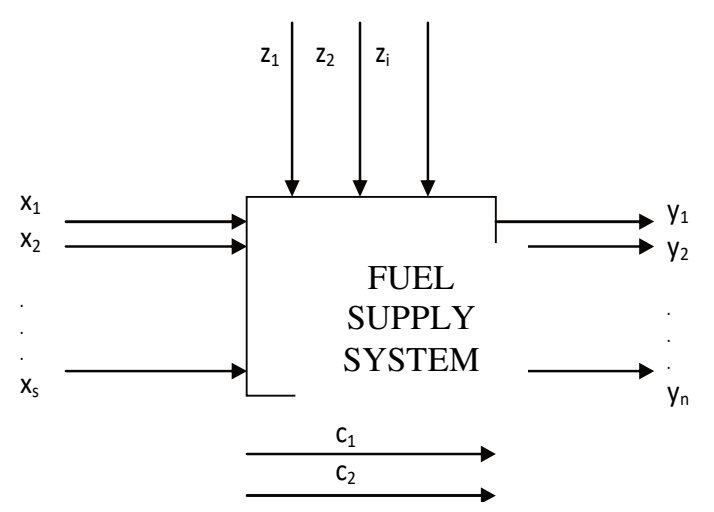

Fig. 1. Quantities characterizing the test subject $\mathrm{x}$ - input quantities, $\mathrm{y}-$ output quantities, $\mathrm{z}$ - disturbances, $\mathrm{c}$ - constant quantities

The statistical identification of both the empiric data and the model data was conducted using the GRETL software [1]. The estimation of the equation factors of the specific output variables was conducted with the help of the least squares method, and its purpose was the verification of the significance of its parameters and, in effect, the discarding of insubstantial values, which, consequently, helped to greatly simplify the models. As a measure of the strength and the direction of the correlation between the observed variables $(\mathrm{Y}, \mathrm{X})$, the linear correlation coefficient of Pearson was adopted.

Correlation coefficients $\mathrm{r}_{\mathrm{yx}_{\mathrm{k}}}$ between the variable $\mathrm{Y}$ and the variables $X_{k}$ make up a vector of correlation coefficients $\mathbf{R}_{\mathbf{0}}$, while, between individual illustrative variables, correlation coefficients $r_{y_{k} x_{s}}$ make up a matrix of correlation coefficients $\mathbf{R}$ (1) of the following form:

$$
\boldsymbol{R}_{\mathbf{0}}=\left[\begin{array}{c}
r_{y x_{1}} \\
r_{y x_{2}} \\
\vdots \\
r_{y x_{K}}
\end{array}\right]_{K \times 1}, \boldsymbol{R}=\left[\begin{array}{cccc}
r_{x_{1} x_{1}} & r_{x_{1} x_{2}} & \ldots & r_{x_{1} x_{K}} \\
r_{x_{2} x_{1}} & r_{x_{1} x_{2}} & \ldots & r_{x_{2} x_{K}} \\
\vdots & \vdots & \ddots & \vdots \\
r_{x_{K} x_{1}} & r_{x_{K} x_{2}} & \cdots & r_{x_{K} x_{K}}
\end{array}\right]_{K \times K}
$$

In the presented analysis of the test results, a substantial merit of the multiequation models comes into view - that is the possibility of a multi-criteria evaluation of the output quantities in the case where these quantities remain in a mutual correlation. Despite their unquestionable advantages, multiequation models do not directly provide the information on the quality of changes, which, in the given situation, are the changes in condensation of individual toxic compounds based on the shifts of the angle of fuel injection advance. Only after compiling the courses of the experiment, or analyzing the produced models, does the image of the phenomenon come into view. Individual correlations along with the fitting of the model to the values received from the experiments held on the engine are presented in further detail in works $[5,6]$.

As mentioned before, the values of condensations of individual condensations of toxic compounds derived from the transient states are characterized by a particular regularity and repeatability. In no way does it make the analysis easier, considering the notable similarity, independent from the values of the excitations of transient state courses. As such, a tool had to be found, which would be able to describe with relative accuracy and objectivity the character of the changes in the toxic compound concentrations. Using this method allows to describe the correlation of the researched transient state with the transient state adopted as the standard describing the given phenomenon. The analysis of the correlation function makes it possible to define the level of correlation as well as its character. Analyzing the components of a function lets us deduce the aforementioned character of the transient state, i.e. the involvement and intensity of its individual phases.

One of the selection methods for illustrative variables (input quantities of the plan of the experiment) for the model, based on the values of the correlation coefficients, is the information capacity index method of Hellwig [6]. This method relies on the choice of a combination of illustrative variables for which the information capacity is the biggest, and all of the potential illustrative variables are considered as information carriers. The experiment scheme itself imposes a suitable number of available combinations, which, in the given case, with the three input values being $\mathrm{K}=3$ $\left(\mathrm{x}_{1}-\right.$ engine speed $\mathrm{n}[\mathrm{r} / \mathrm{min}] ; \mathrm{x}_{2}-$ engine torque $\mathrm{T}_{\mathrm{tq}}[\mathrm{N} \cdot \mathrm{m}]$; $\mathrm{x}_{3}-$ angle of fuel injection advance $\alpha_{\mathrm{ww}}\left[{ }^{\circ} \mathrm{OWK}\right]$ ), is as follows:

$$
\mathrm{L}(\mathrm{K})=2^{\mathrm{K}}-1
$$


Thus created are (for each of the illustrated - output variables) the following combinations:

- one-element: $\mathrm{C}_{1}=\left\{\mathrm{X}_{1}\right\}, \mathrm{C}_{2}=\left\{\mathrm{X}_{2}\right\}, \mathrm{C}_{3}=\left\{\mathrm{X}_{3}\right\}$,

- two-element: $\mathrm{C}_{4}=\left\{\mathrm{X}_{1}, \mathrm{X}_{2}\right\}, \mathrm{C}_{5}=\left\{\mathrm{X}_{1}, \mathrm{X}_{3}\right\}, \mathrm{C}_{6}=\left\{\mathrm{X}_{2}\right.$, $\left.\mathrm{X}_{3}\right\}$

- three-element: $C_{7}=\left\{X_{1}, X_{2}, X_{3}\right\}$.

For each of the combinations mentioned above, an individual information capacity index $h_{m x_{k}}$ for the variable $X_{k}$ in the $\mathrm{m}^{\text {th }}$ variable combination must be defined:

$$
h_{m x_{k}}=\frac{r_{y x_{k}}^{2}}{1+\sum_{\substack{k, s \in K_{m} \\ k \neq s}}\left|r_{x_{k} x_{s}}\right|}
$$

where: $\mathrm{r}_{\mathrm{yx}_{\mathrm{k}}}$ - correlation coefficient between the illustrated variable $Y$ and the illustrative variable $X_{k}$ (correlation coefficient matrix $\mathbf{R}_{\mathbf{0}}$ ), $\mathrm{r}_{\mathrm{x}_{\mathrm{k}} \mathrm{x}_{\mathrm{s}}}$ - correlation coefficient between the illustrative variables (correlation coefficient matrix $\mathbf{R}$ ), $\mathrm{m}$ - number of combinations, $\mathrm{k}$ - number of illustrative variable $X_{k}$, for which the individual information capacity index $h_{m_{k}}$ is being calculated.

The next step in the Hellwig analysis is calculating for each of the combinations the integral information capacity index $\mathrm{H}_{\mathrm{m}}$

$$
\mathrm{H}_{\mathrm{m}}=\sum_{\mathrm{k} \in \mathrm{K}} \mathrm{h}_{\mathrm{mx}_{\mathrm{k}}}
$$

The highest value for this index makes up for the criterion for the choice of the suitable combination between the illustrative variables. Of course, taking into consideration the goal of this analysis, i.e.: the identification of the sensitivity of diagnostic parameters, which are the concentrations of the individual gas components of exhausts on the changes of parameters of the structure that was the angle of fuel injection advance, particular care was taken during the analysis of the input parameter combinations. These systems were $\mathrm{C}_{3}, \mathrm{C}_{5}, \mathrm{C}_{6}$ and $\mathrm{C}_{7}$.

Considering that the majority of the gathered empirical material and the limited form of this paper, the analysis of the information capacity index's variability was limited to one engine speed only, i.e.: $\mathrm{n}=1100 \mathrm{r} / \mathrm{min}$. Compounds which were the subject of this analysis were concentrations of $\mathrm{HC}, \mathrm{CO}, \mathrm{NO}_{\mathrm{x}}$. Analyzed were also the changes in excess air number $\lambda$.

The highest values of the $\mathrm{H}_{\mathrm{m}}$ index were observed for the excess air number $\lambda$, followed by carbon oxide $\mathrm{CO}$ concentration and the unburned hydrocarbons HC. The lowest values of $\mathrm{H}_{\mathrm{m}}$ were present for nitric oxides $\mathrm{NO}_{\mathrm{x}}$.

It should be noted that the observed regularity, namely the higher values of the $\mathrm{H}_{\mathrm{m}}$ index were observed for the delayed fuel injection angle $\left(22^{\circ} \mathrm{CA}\right)$, which of course has a substantive justification, because the delayed angle of injection adversely affects the change in combustion conditions. In the first place, the value of the excess air ratio decreases, resulting in the formation of incomplete combustion products, thus increasing the concentration of $\mathrm{CO}$ and $\mathrm{HC}$.

The correct estimation of the model is also shown through a negative correlation, both in the case of air abundance and $\mathrm{NO}_{\mathrm{x}}$ concentration, as local oxygen deficiency is a factor reducing the concentration of this compound.

The highest values of the $\mathrm{H}_{\mathrm{m}}$ index belong primarily to the $\mathrm{C}_{5}$ combination, which involves the rotational speed $\left(\mathrm{x}_{1}\right)$ and the engine structure parameter, which was the fuel injection advance angle $\left(\mathrm{x}_{3}\right)$, for both accelerated and delayed fuel injection. Slightly lower $\mathrm{H}_{\mathrm{m}}$ values are present for the $\mathrm{C}_{7}$ combination which combines the three input values of the experiment plan (Figs 2-5).

The analysis of the integral information capacity index value $\mathrm{H}_{\mathrm{m}}$ gives us not only the possibility of an accurate estimation of the model (which is its intended use) but also, thanks to this analysis, it is possible to define, from a vast pool of data, the conditions in which the impact on the researched subject is the greatest. Nevertheless, the values of the $\mathrm{H}_{\mathrm{m}}$ index, relatively close to each other in numbers, are making difficult the deduction of which of the experiment plans wields the maximum information value, especially when they are only referring to one parameter or one combination of said parameters.
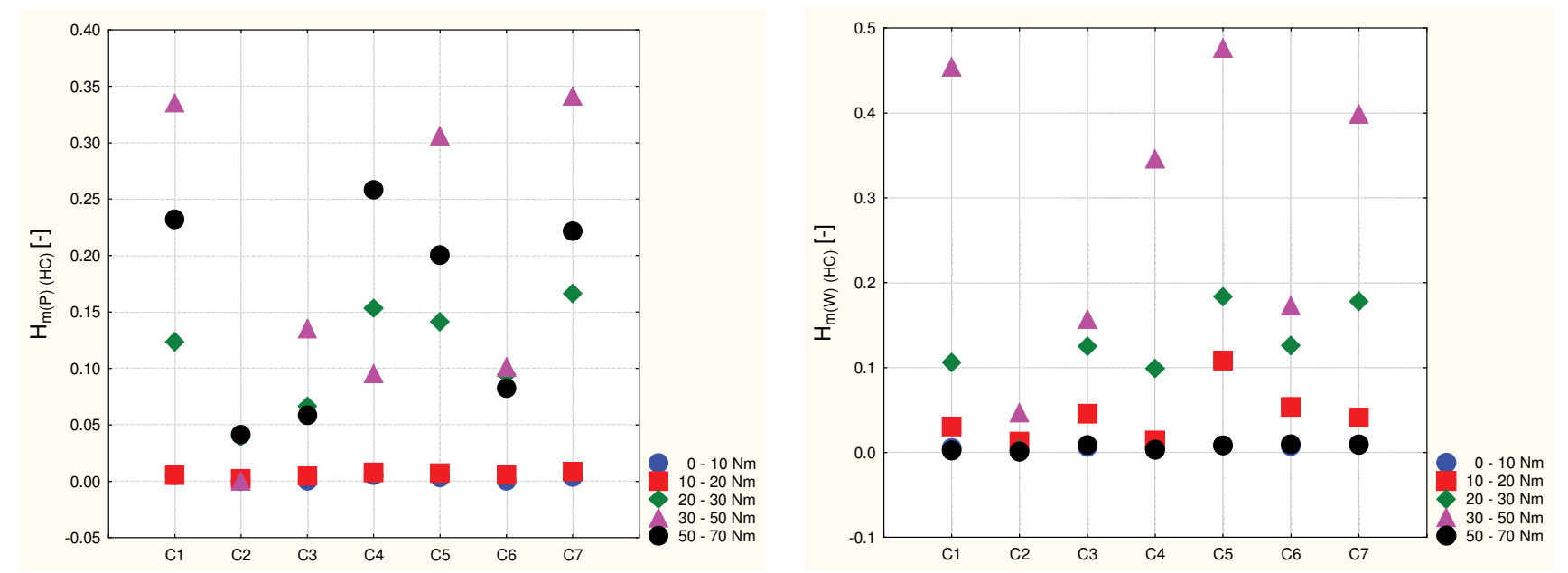

Fig. 2. Values of the information capacity index $H_{m}$ for $\mathrm{HC}$ and the transient state at $n=1100 \mathrm{r} / \mathrm{min}$ and a change of load from $T_{\mathrm{tq}}=0 \mathrm{Nm}$ to $T_{\mathrm{tq}}=70 \mathrm{Nm}$ : $\mathrm{P}$ - delayed angle of injection advance; $\mathrm{W}$ - accelerated angle of injection advance; $\mathrm{C}_{1}-\mathrm{C}_{7}$ - combinations of illustrative variables 

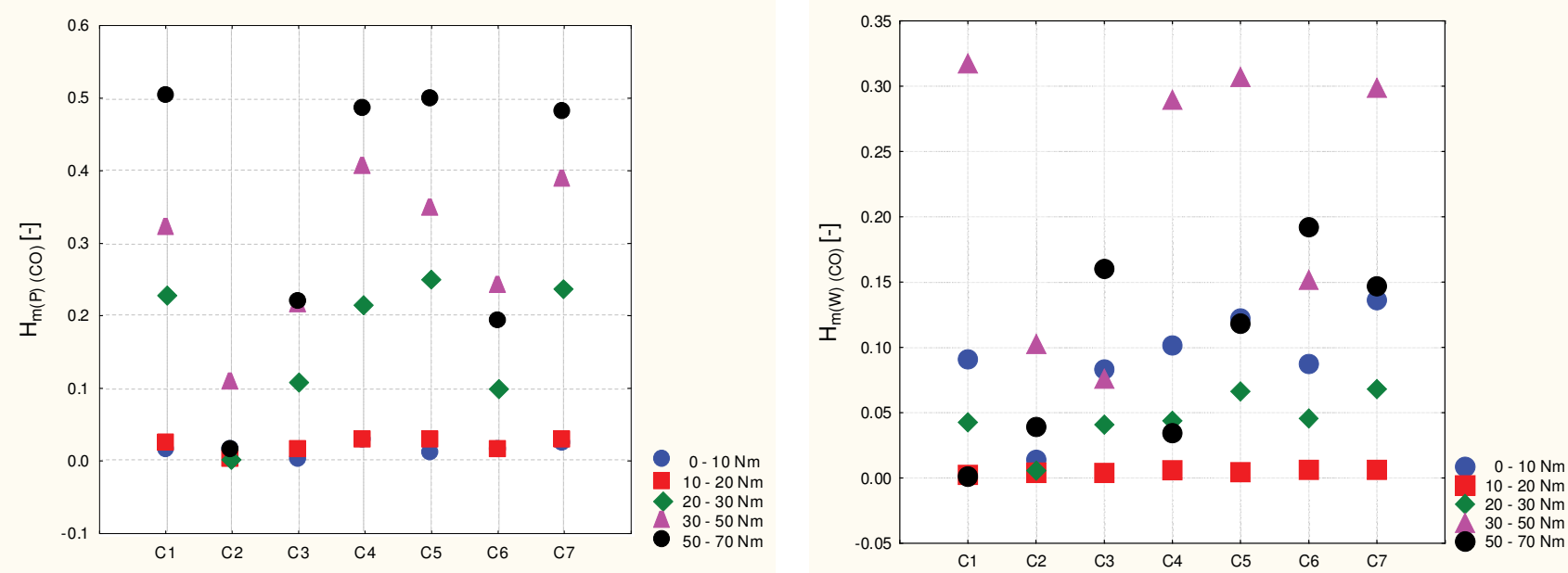

Fig. 3. Values of the information capacity index $H_{m}$ for $\mathrm{CO}$ and the transient state at $n=1100 \mathrm{r} / \mathrm{min}$ and a change of load from $T_{\mathrm{tq}}=0 \mathrm{Nm}$ to $T_{\mathrm{tq}}=70 \mathrm{Nm}$ : $\mathrm{P}$ - delayed angle of injection advance; $\mathrm{W}$ - accelerated angle of injection advance; $\mathrm{C}_{1}-\mathrm{C}_{7}$ - combinations of illustrative variables
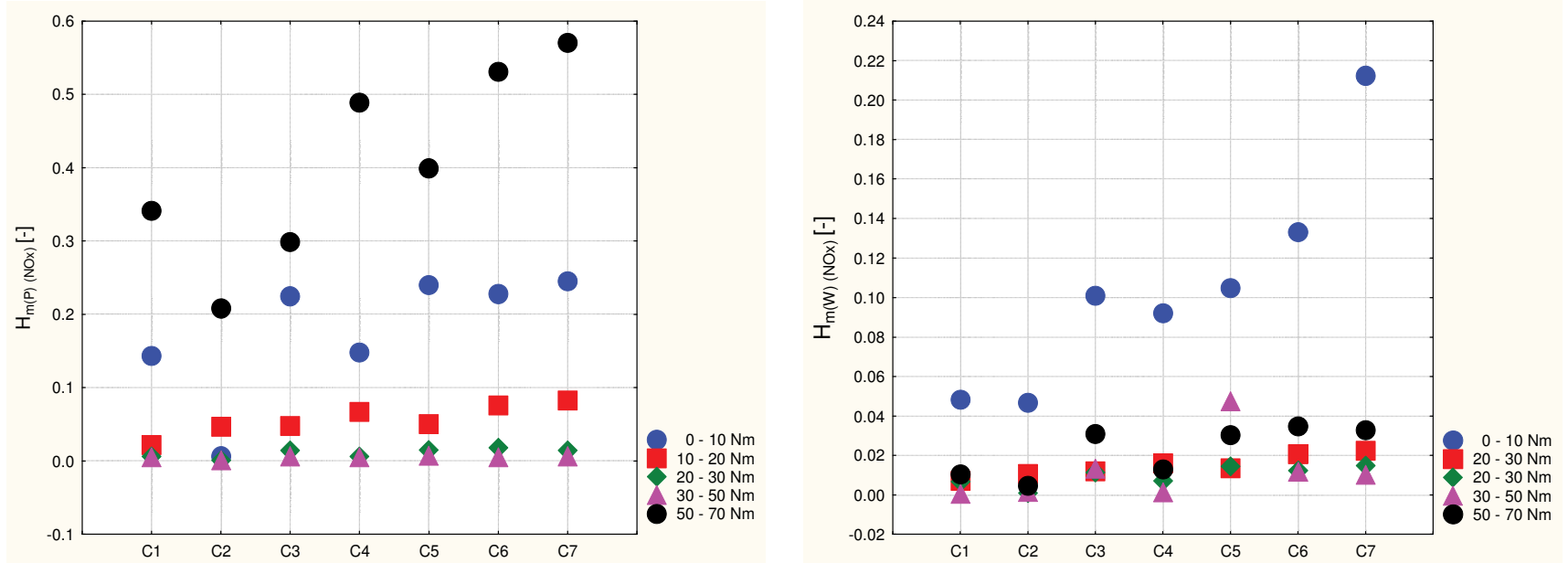

Fig. 4. Values of the information capacity index $\mathrm{H}_{\mathrm{m}}$ for $\mathrm{NO}_{\mathrm{x}}$ and the transient state at $\mathrm{n}=1100 \mathrm{r} / \mathrm{min}$ and a change of load from $\mathrm{T}_{\mathrm{tq}}=0 \mathrm{Nm}$ to $\mathrm{T}_{\mathrm{tq}}=70$ $\mathrm{Nm}$ : $\mathrm{P}$ - delayed angle of injection advance; $\mathrm{W}$ - accelerated angle of injection advance; $\mathrm{C}_{1}-\mathrm{C}_{7}-$ combinations of illustrative variables
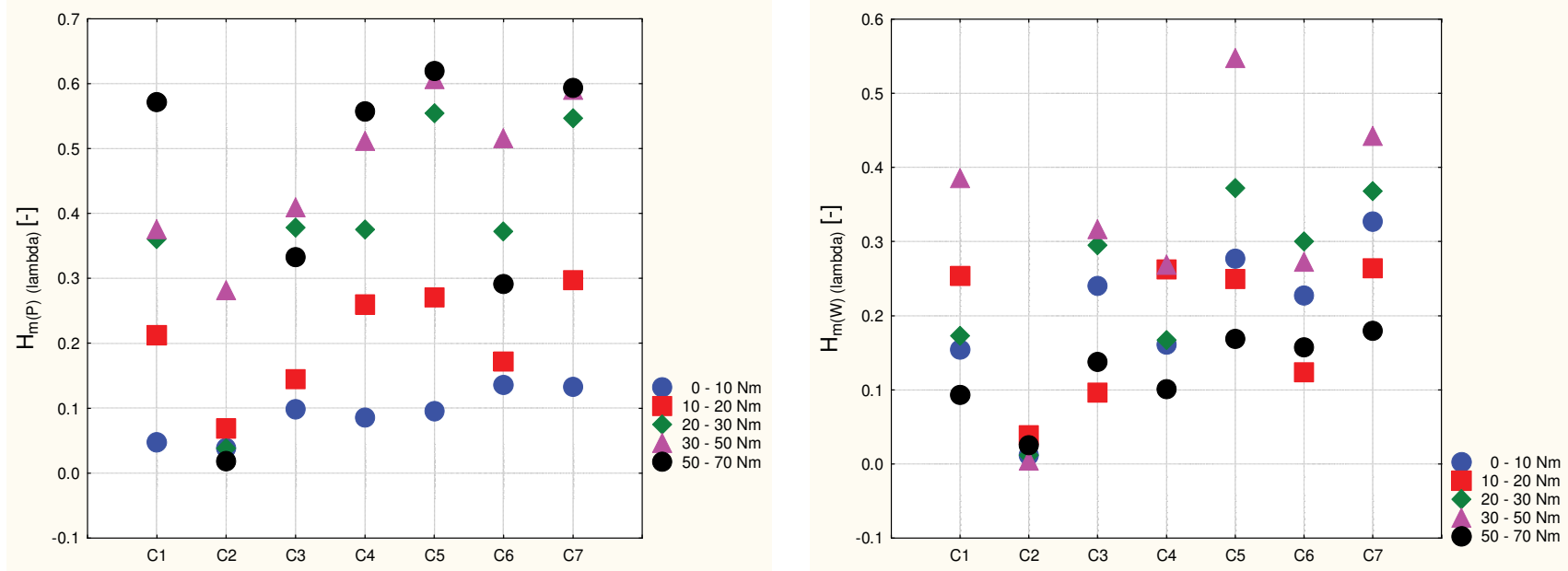

Fig. 5. Values of the information capacity index $H_{m}$ for $\lambda$ and the transient state at $n=1100 \mathrm{r} / \mathrm{min}$ and a change of load from $T_{t q}=0 \mathrm{Nm}$ to $T_{t q}=70 \mathrm{Nm}: P$ - delayed angle of injection advance; $\mathrm{W}$ - accelerated angle of injection advance; $\mathrm{C}_{1}-\mathrm{C}_{7}$ - combinations of illustrative variables 
In the above mentioned situation, using a parameter ranking seems to be a helpful option, as a ranking reflecting the multi-criteria evaluations (which includes all of the parameters and their combinations) is one of the main premises of making accurate diagnostic decisions.

\section{Building a ranking}

Taking into account the large quantities of the research material as well as the need of an objective indication of the most favourable diagnostic parameter, considering its sensitivity, a ranking was built on the basis of the zero unitization method. Because earlier each of the illustrative variables for the experiment scheme was run through the Hellwig's information capacity index method analysis, in the early stages of the creation of the ranking it was assumed that the diagnostic variables of the individual illustrative variables will be taken from the Hellwig's index values. These values, for the individual systems and input parameter combinations, are shown in Table 1.

The first step to building the ranking was the division of the diagnostic variable set into three subsets: S, D i N, i.e.:

$$
\mathrm{X}=\mathrm{S} \cup \mathrm{D} \cup \mathrm{N}
$$

where: $\mathrm{S}$ - subset of diagnostic variables called the stimulators, D - subset of diagnostic variables called the destimulators, $\mathrm{N}$ - subset of diagnostic variables called the nominants.

The transformation of stimulants into the normalized form was calculated using the correlation:

$$
z_{i j}=\frac{x_{i j}-\min _{i} x_{i j}}{\max _{i} x_{i j}-\min _{i} x_{i j}}, \quad\left(\begin{array}{l}
i=1,2, \ldots, r \\
j=1,2, \ldots, s
\end{array}\right), X_{i} \in S,
$$

respectively, the correlation used for destimulants:

$$
z_{i j}=\frac{\max _{i} x_{i j}-x_{i j}}{\max _{i} x_{i j}-\min _{i} x_{i j}}, \quad\left(\begin{array}{l}
i=1,2, \ldots, r \\
j=1,2, \ldots, s
\end{array}\right), \quad X_{i} \in D
$$

Chosen as the stimulants, that is, the diagnostic variables whose growth should be associated with an increase, while the drop with a decrease of the evaluation of a complex phenomenon, were the combinations of illustrated variables $\mathrm{C}_{1}, \mathrm{C}_{3}, \mathrm{C}_{4}, \mathrm{C}_{5}, \mathrm{C}_{7}$. While the chosen destimulants, that is, the diagnostic variables whose growth is associated with a decrease, while the drop with an increase of the complex phenomenon, were the combinations $\mathrm{C}_{2}$ and $\mathrm{C}_{6}$.

In the case of building a ranking which reflects the mutual interactions of individual exhaust components (which is the case presented in this paper) as well as a ranking which reflects the changes of the structure parameters (changed angle of fuel injection advance), the parameter should be added to the subset of nominants, whose normalization should proceed as follows:

$$
z_{i j}=\left\{\begin{array}{cc}
\frac{x_{i j}-\min _{i} x_{i j}}{c_{0 j}-\min _{i} x_{i j}}, & \text { when } x_{i j}<c_{0 j}, \\
1, & \text { when } x_{i j}=c_{0 j}, x_{i} \in N, \\
\frac{x_{i j}-\max _{i} x_{i j}}{c_{0 j}-\max _{i} x_{i j}}, & \text { when } x_{i j}>c_{0 j}
\end{array}\right.
$$

The following step was the creation of the diagnostic characteristic normalization. This step is essential as it allows for receiving a linked multi-criteria evaluation of the analyzed subject. The linked evaluation is reached through aggregation, i.e., setting an aggregate (synthetic) variable $Q_{i}$.

$$
\mathrm{Q}_{\mathrm{i}}=\frac{1}{\mathrm{~s}} \sum_{\mathrm{j}=1}^{\mathrm{s}} \mathrm{z}_{\mathrm{ij}} \quad(\mathrm{i}=1,2, \ldots, \mathrm{r})
$$

Knowledge of the variable $Q$ allows building a ranking relative to the non-increasing $\mathrm{Q}_{\mathrm{i}}$ values. As expected, the order of the ranking will be determined by the value of the synthetic variable $Q_{i}$, which is presented in Table 5-8.

By analyzing the tables containing the values of standardized diagnostic variables, it can be seen that the highest values are found for systems with a delayed fuel injection angle of $22^{\circ} \mathrm{CA}$, both for the concentrations of $\mathrm{CO}, \mathrm{NO}_{\mathrm{x}}$ and the excess air number $\lambda$. The characteristic layout of the experiment plan is the $1100 \mathrm{P}(50-70)$ system, which is implemented for a transient state at a rotational speed of 1100 $\mathrm{r} / \mathrm{min}$, with a load change of 50 to $70 \mathrm{Nm}$ and for delayed fuel injection, which is $22^{\circ} \mathrm{CA}$ (Table 6-8). Other systems in the ranking of information values (slightly lower), which are characterized by high values of standardized diagnostic variables, are intermediate load systems, i.e.: firstly when the load is changed from 20 to $30 \mathrm{Nm}$ and secondly from 30 to $50 \mathrm{Nm}$. This mainly concerns the changes in $\mathrm{CO}$ concentration and the value of the excess air number $\lambda$. In the case of $\mathrm{NO}_{\mathrm{x}}$ concentration (Table 7), systems are followed by other systems that are implemented for similar load changes but for an accelerated fuel injection advance angle $\left(30^{\circ} \mathrm{CA}\right)$. This has its substantive justification stemming from the physics of creating individual toxic compounds in the cylinder. Thus, for nitrogen oxides, the domi-

\begin{tabular}{|c|c|c|c|c|c|c|c|}
\hline Plan system & $\mathrm{C}_{1}$ & $\mathrm{C}_{2}$ & $\mathrm{C}_{3}$ & $\mathrm{C}_{4}$ & $\mathrm{C}_{5}$ & $\mathrm{C}_{6}$ & $\mathrm{C}_{7}$ \\
\hline 1 & 2 & 3 & 4 & 5 & 6 & 7 & 8 \\
\hline $1100 \mathrm{P}(50-70)$ & 0.2318 & 0.0416 & 0.0586 & 0.2583 & 0.2001 & 0.0826 & 0.2217 \\
\hline $1100 \mathrm{P}(30-50)$ & 0.3350 & 0.0004 & 0.1351 & 0.0956 & 0.3060 & 0.1009 & 0.3412 \\
\hline $1100 \mathrm{P}(20-30)$ & 0.1236 & 0.0392 & 0.0665 & 0.1532 & 0.1412 & 0.0944 & 0.1664 \\
\hline $1100 \mathrm{P}(10-20)$ & 0.0053 & 0.0024 & 0.0049 & 0.0076 & 0.0075 & 0.0058 & 0.0087 \\
\hline $1100 \mathrm{~W}(50-70)$ & 0.0027 & 0.0015 & 0.0087 & 0.0036 & 0.0084 & 0.0098 & 0.0092 \\
\hline $1100 \mathrm{~W}(30-50)$ & 0.4545 & 0.0471 & 0.1570 & 0.3458 & 0.4768 & 0.1734 & 0.3988 \\
\hline $1100 \mathrm{~W}(20-30)$ & 0.1059 & 0.0037 & 0.1252 & 0.0989 & 0.1835 & 0.1261 & 0.1784 \\
\hline $1100 \mathrm{~W}(10-20)$ & 0.0304 & 0.0130 & 0.0456 & 0.0144 & 0.1086 & 0.0536 & 0.0414 \\
\hline
\end{tabular}
nant mode of their formation is primarily the high combustion pressure, with a significant excess air number, and the high combustion temperature associated with that pressure.

Table 1. Numerical values of the diagnostic variables for $\mathrm{HC}$ concentration 
Table 2. Numerical values of the diagnostic variables for $\mathrm{CO}$ concentration

\begin{tabular}{|c|c|c|c|c|c|c|c|}
\hline Plan system & $\mathrm{C}_{1}$ & $\mathrm{C}_{2}$ & $\mathrm{C}_{3}$ & $\mathrm{C}_{4}$ & $\mathrm{C}_{5}$ & $\mathrm{C}_{6}$ & $\mathrm{C}_{7}$ \\
\hline 1 & 2 & 3 & 4 & 5 & 6 & 7 & 8 \\
\hline $1100 \mathrm{P}(50-70)$ & 0.5049 & 0.0169 & 0.2176 & 0.4859 & 0.4975 & 0.1947 & 0.4791 \\
\hline $1100 \mathrm{P}(30-50)$ & 0.3204 & 0.1096 & 0.2142 & 0.4067 & 0.3478 & 0.2413 & 0.3889 \\
\hline $1100 \mathrm{P}(20-30)$ & 0.2272 & 0.0008 & 0.1102 & 0.2146 & 0.2507 & 0.0995 & 0.2374 \\
\hline $1100 \mathrm{P}(10-20)$ & 0.0264 & 0.0021 & 0.0149 & 0.0280 & 0.0300 & 0.0136 & 0.0298 \\
\hline $1100 \mathrm{~W}(50-70)$ & 0.0013 & 0.0390 & 0.1602 & 0.0343 & 0.1182 & 0.1919 & 0.1470 \\
\hline $1100 \mathrm{~W}(30-50)$ & 0.3176 & 0.1028 & 0.0763 & 0.2898 & 0.3072 & 0.1521 & 0.2988 \\
\hline $1100 \mathrm{~W}(20-30)$ & 0.0426 & 0.0056 & 0.0410 & 0.0440 & 0.0664 & 0.0456 & 0.0682 \\
\hline $1100 \mathrm{~W}(10-20)$ & 0.0025 & 0.0042 & 0.0039 & 0.0060 & 0.0046 & 0.0064 & 0.0063 \\
\hline
\end{tabular}

Table 3. Numerical values of the diagnostic variables for $\mathrm{NO}_{\mathrm{x}}$ concentration

\begin{tabular}{|c|c|c|c|c|c|c|c|}
\hline Plan system & $\mathrm{C}_{1}$ & $\mathrm{C}_{2}$ & $\mathrm{C}_{3}$ & $\mathrm{C}_{4}$ & $\mathrm{C}_{5}$ & $\mathrm{C}_{6}$ & $\mathrm{C}_{7}$ \\
\hline 1 & 2 & 3 & 4 & 5 & 6 & 7 & 8 \\
\hline $1100 \mathrm{P}(50-70)$ & 0.3412 & 0.2081 & 0.2986 & 0.4889 & 0.3488 & 0.5312 & 0.5705 \\
\hline $1100 \mathrm{P}(30-50)$ & 0.0048 & 0.0047 & 0.0062 & 0.0047 & 0.0071 & 0.0049 & 0.0065 \\
\hline $1100 \mathrm{P}(20-30)$ & 0.0059 & 0.0003 & 0.0140 & 0.0059 & 0.0148 & 0.0178 & 0.0141 \\
\hline $1100 \mathrm{P}(10-20)$ & 0.0213 & 0.0464 & 0.0477 & 0.0665 & 0.0501 & 0.0756 & 0.0826 \\
\hline $1100 \mathrm{~W}(50-70)$ & 0.0106 & 0.0047 & 0.0309 & 0.0130 & 0.0304 & 0.0348 & 0.0328 \\
\hline $1100 \mathrm{~W}(30-50)$ & 0.0006 & 0.0016 & 0.0133 & 0.0015 & 0.0476 & 0.0118 & 0.0103 \\
\hline $1100 \mathrm{~W}(20-30)$ & 0.0069 & 0.0010 & 0.0115 & 0.0071 & 0.0146 & 0.0123 & 0.0148 \\
\hline $1100 \mathrm{~W}(10-20)$ & 0.0071 & 0.0107 & 0.0119 & 0.0160 & 0.0136 & 00207 & 0.0224 \\
\hline
\end{tabular}

Table 4. Numerical values of the diagnostic variables for $\lambda$

\begin{tabular}{|c|c|c|c|c|c|c|c|}
\hline Plan system & $\mathrm{C}_{1}$ & $\mathrm{C}_{2}$ & $\mathrm{C}_{3}$ & $\mathrm{C}_{4}$ & $\mathrm{C}_{5}$ & $\mathrm{C}_{6}$ & $\mathrm{C}_{7}$ \\
\hline 1 & 2 & 3 & 4 & 5 & 6 & 7 & 8 \\
\hline $1100 \mathrm{P}(50-70)$ & 0.5714 & 0.0187 & 0.3324 & 0.6194 & 0.6194 & 0.2914 & 05938 \\
\hline $1100 \mathrm{P}(30-50)$ & 0.3761 & 0.2819 & 0.4101 & 0.5113 & 0.6073 & 0.5156 & 05906 \\
\hline $1100 \mathrm{P}(20-30)$ & 0.3608 & 0.0383 & 0.3781 & 0.3756 & 0.5544 & 0.3722 & 0.5468 \\
\hline $1100 \mathrm{P}(10-20)$ & 0.2628 & 0.0048 & 0.0982 & 0.2370 & 0.2389 & 0.2106 & 0.2367 \\
\hline $1100 \mathrm{~W}(50-70)$ & 0.0934 & 0.0254 & 0.1381 & 0.1012 & 0.1693 & 0.1575 & 0.1799 \\
\hline $1100 \mathrm{~W}(30-50)$ & 0.3859 & 0.0046 & 0.3167 & 0.2692 & 0.5478 & 0.2730 & 0.4426 \\
\hline $1100 \mathrm{~W}(20-30)$ & 0.1738 & 0.0119 & 0.2954 & 0.1672 & 0.3722 & 0.3007 & 0.3679 \\
\hline $1100 \mathrm{~W}(10-20)$ & 0.2538 & 0.0391 & 0.0963 & 0.2627 & 0.2501 & 0.1239 & 0.2642 \\
\hline
\end{tabular}

Table 5. Normalized values of diagnostic variables and value of the synthetic variable for $\mathrm{HC}$

\begin{tabular}{|c|c|c|c|c|c|c|c|c|}
\hline Plan system & $\mathrm{C}_{1}$ & $\mathrm{C}_{2}$ & $\mathrm{C}_{3}$ & $\mathrm{C}_{4}$ & $\mathrm{C}_{5}$ & $\mathrm{C}_{6}$ & $\mathrm{C}_{7}$ & $\mathrm{Q}_{\mathrm{i}}$ \\
\hline 1 & 2 & 3 & 4 & 5 & 6 & 7 & 8 & 9 \\
\hline $1100 \mathrm{P}(50-70)$ & 0.5071 & 0.1178 & 0.3531 & 0.7443 & 0.4104 & 0.5418 & 0.5460 & 3.2205 \\
\hline $1100 \mathrm{P}(30-50)$ & 0.7355 & 1 & 0.8560 & 0.2688 & 0.6361 & 0.4326 & 0.8523 & 4.7813 \\
\hline $1100 \mathrm{P}(20-30)$ & 0.2676 & 0.1692 & 0.4050 & 0.4372 & 0.2849 & 0.4714 & 0.4043 & 2.4396 \\
\hline $1100 \mathrm{P}(10-20)$ & 0.0058 & 0.9571 & 0 & 0.0117 & 0 & 1 & 0 & 1.9746 \\
\hline $1100 \mathrm{~W}(50-70)$ & 0 & 0.9764 & 0.0250 & 0 & 0.0020 & 0.9761 & 0.0013 & 1.9808 \\
\hline $1100 \mathrm{~W}(30-50)$ & 1 & 0 & 1 & 1 & 1 & 0 & 1 & 5.0 \\
\hline $1100 \mathrm{~W}(20-30)$ & 0.2284 & 0.9293 & 0.7909 & 0.2785 & 0.3750 & 0.2822 & 0.4350 & 3.3193 \\
\hline $1100 \mathrm{~W}(10-20)$ & 0.0613 & 0.7302 & 0.2676 & 0.0316 & 0.2154 & 0.7148 & 0.0838 & 2.1047 \\
\hline
\end{tabular}

Table 6. Normalized values of diagnostic variables and value of the synthetic variable for $\mathrm{CO}$

\begin{tabular}{|c|c|c|c|c|c|c|c|c|}
\hline Plan system & $\mathrm{C}_{1}$ & $\mathrm{C}_{2}$ & $\mathrm{C}_{3}$ & $\mathrm{C}_{4}$ & $\mathrm{C}_{5}$ & $\mathrm{C}_{6}$ & $\mathrm{C}_{7}$ & $\mathrm{Q}_{\mathrm{i}}$ \\
\hline 1 & 2 & 3 & 4 & 5 & 6 & 7 & 8 & 9 \\
\hline $1100 \mathrm{P}(50-70)$ & 1 & 0.8520 & 1 & 1 & 1 & 0.1983 & 1 & 6.0503 \\
\hline $1100 \mathrm{P}(30-50)$ & 0.6336 & 0 & 0.9841 & 0.8349 & 0.6928 & 0 & 0.3826 & 3.5280 \\
\hline $1100 \mathrm{P}(20-30)$ & 0.4485 & 1 & 0.4974 & 0.4346 & 0.4992 & 0.6036 & 0.4887 & 3.9720 \\
\hline $1100 \mathrm{P}(10-20)$ & 0.0498 & 0.9880 & 0.0515 & 0.0458 & 0.0515 & 0.9693 & 0.0497 & 2.2056 \\
\hline $1100 \mathrm{~W}(50-70)$ & 0 & 0.6488 & 0.7314 & 0.0589 & 0.2304 & 0.2103 & 0.2975 & 2.1773 \\
\hline $1100 \mathrm{~W}(30-50)$ & 0.6280 & 0.0625 & 0.3388 & 0.5913 & 0.6139 & 0.3797 & 0.6186 & 3.2328 \\
\hline $1100 \mathrm{~W}(20-30)$ & 0.0820 & 0.9558 & 0.1736 & 0.0791 & 0.1253 & 0.8331 & 0.1309 & 2.3798 \\
\hline $1100 \mathrm{~W}(10-20)$ & 0.0023 & 0.9687 & 0 & 0 & 0 & 0 & 0 & 0.9710 \\
\hline
\end{tabular}

Table 7. Normalized values of diagnostic variables and value of the synthetic variable for $\mathrm{NO}_{\mathrm{x}}$

\begin{tabular}{|c|c|c|c|c|c|c|c|c|}
\hline Plan system & $\mathrm{C}_{1}$ & $\mathrm{C}_{2}$ & $\mathrm{C}_{3}$ & $\mathrm{C}_{4}$ & $\mathrm{C}_{5}$ & $\mathrm{C}_{6}$ & $\mathrm{C}_{7}$ & $\mathrm{Q}_{\mathrm{i}}$ \\
\hline 1 & 2 & 3 & 4 & 5 & 6 & 7 & 8 & 9 \\
\hline $1100 \mathrm{P}(50-70)$ & 1 & 0 & 1 & 1 & 1 & 0 & 1 & 5.0000 \\
\hline $1100 \mathrm{P}(30-50)$ & 0.0123 & 0.9995 & 0 & 0.0065 & 0 & 1 & 0 & 2.0183 \\
\hline $1100 \mathrm{P}(20-30)$ & 0.0146 & 1 & 0.0266 & 0.0090 & 0.0225 & 0.9754 & 0.0134 & 2.0615 \\
\hline $1100 \mathrm{P}(10-20)$ & 0.0607 & 0.2218 & 0.1419 & 0.1333 & 0.1258 & 0.8656 & 0.1349 & 1.6840 \\
\hline $1100 \mathrm{~W}(50-70)$ & 0.0293 & 0.9788 & 0.0844 & 0.0236 & 0.0681 & 0.9431 & 0.0466 & 2.1739 \\
\hline $1100 \mathrm{~W}(30-50)$ & 0 & 0.9937 & 0.0242 & 0 & 0.1185 & 0.9868 & 0.0067 & 2.1299 \\
\hline $1100 \mathrm{~W}(20-30)$ & 0.0184 & 0.9951 & 0.0181 & 0.0114 & 0.0219 & 0.9859 & 0.0147 & 1.0339 \\
\hline $1100 \mathrm{~W}(10-20)$ & 0.0191 & 0.9499 & 0.0194 & 0.0297 & 0.0190 & 0.9699 & 0.2819 & 2.2889 \\
\hline
\end{tabular}


Table 8 . Normalized values of diagnostic variables and value of the synthetic variable for $\lambda$

\begin{tabular}{|c|c|c|c|c|c|c|c|c|}
\hline Plan system & $\mathrm{C}_{1}$ & $\mathrm{C}_{2}$ & $\mathrm{C}_{3}$ & $\mathrm{C}_{4}$ & $\mathrm{C}_{5}$ & $\mathrm{C}_{6}$ & $\mathrm{C}_{7}$ & $\mathrm{Q}_{\mathrm{i}}$ \\
\hline 1 & 2 & 3 & 4 & 5 & 6 & 7 & 8 & 9 \\
\hline $1100 \mathrm{P}(50-70)$ & 1 & 0.2631 & 0.7524 & 1 & 1 & 0.5723 & 1 & 5.5878 \\
\hline $1100 \mathrm{P}(30-50)$ & 0.5914 & 0 & 1 & 0.9000 & 0.9731 & 0 & 0.9922 & 4.4567 \\
\hline $1100 \mathrm{P}(20-30)$ & 0.5594 & 0.8784 & 0.8980 & 0.6013 & 0.8556 & 0.3661 & 0.8864 & 5.0452 \\
\hline $1100 \mathrm{P}(10-20)$ & 0.3544 & 0.9992 & 0.0061 & 0.2976 & 0.0696 & 0.7786 & 0.1372 & 2.6427 \\
\hline $1100 \mathrm{~W}(50-70)$ & 0 & 0.9249 & 0.1332 & 0 & 0 & 0.9142 & 0 & 1.9723 \\
\hline $1100 \mathrm{~W}(30-50)$ & 0.6119 & 1 & 0.7024 & 0.3682 & 0.8409 & 0.6193 & 0.6347 & 4.7774 \\
\hline $1100 \mathrm{~W}(20-30)$ & 0.1672 & 0.9736 & 0.6345 & 0.1446 & 0.4508 & 0.5486 & 0.4542 & 3.3735 \\
\hline $1100 \mathrm{~W}(10-20)$ & 0.3356 & 0.8755 & 0 & 0.3539 & 0.1795 & 1 & 0.2037 & 2.9482 \\
\hline
\end{tabular}

In the case of hydrocarbon concentration (Table 5), it can be seen, similarly to the $\mathrm{NO}_{\mathrm{x}}$ concentration (except for the first system), that the highest values occur in the experiment plan of $1100 \mathrm{~W}(30-50)$, that is transient state created at $1100 \mathrm{r} / \mathrm{min}$, with a load change from 30 to $50 \mathrm{Nm}$ and for accelerated fuel injection which was $3^{\circ} \mathrm{CA}$. This may indicate that this system carries the greatest information value.

The 1100P(30-50) system will hold the next rank of the information value (slightly lower) due to changes in the fuel supply system structure. It should be noted that in both cases these are not the systems with the highest torque values. The conclusion is that intermediate test systems may play an important role in the design of diagnostic tests. Only the next, third system in the ranking, is one that is realized at the maximum torque load.

\section{Summary}

The numerically similar values of the $H_{m}$ index do not provide answers as to which of the experiment plan systems carry the maximum information value, considering the changes in the test subject structure, especially when they only adhere to one parameter or one combination of said parameters. However, a ranking reflecting multi-criteria evaluations (encompassing all of the parameters and their combinations) is easily one of the fundamental premises of making accurate diagnostic decisions. Of course, it is viable to build a more in-depth ranking, taking into consideration, for example, a nominant diagnostic variable and its subset of nominal values, which will mirror the state of the engine in its full aptitude. It is also possible to create a more complex set of illustrative and illustrated variables so that the ranking could encompass all of the toxic compound parameters registered during the course of the testing, including the excess air number $\lambda$.

Directly regarding the results of the ranking, a regularity should be noted. The higher values of synthetic variable $Q_{i}$ were observed, except for the very highest value, for the delayed angle of fuel injection $\left(22^{\circ} \mathrm{CA}\right)$, which has its substantial justification, as the delayed angle of injection unfavourably influences the change in the combustion conditions. At first the value of the excess air number lowers, which causes the creation of incomplete combustion products, i.e., an increase of $\mathrm{HC}$ concentration, which comprised the main subject of this analysis.

\section{Bibliography}

[1] RUDNICKI, J., ZADRĄG, R. Problems of modelling toxic compounds emitted by a marine internal combustion engine in unsteady states. Polish Maritime Research. 2014, 21, 5765.

[2] ZADRĄG, R. Criteria for the selection of the diagnostic parameter for diagnosis of marine diesel engine. Logistyka. $2010,4$.

[3] ZADRĄG, R., ZELLMA, M. Modelling of toxic compounds emission in marine diesel engine during transient states at

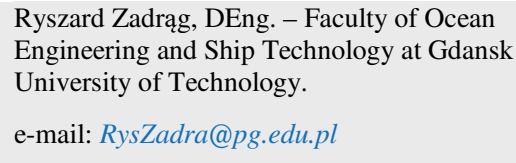

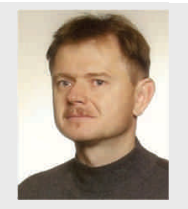

variable pressure of fuel injection. Journal of Polisch CIMAC. 2014, 8(1).

[4] ZADRĄG, R., KNIAZIEWICZ, T. The identification of toxic compound emission sensitivity as a diagnostic parameter during dynamic processes of the marine engine. Journal of Polish CIMAC. 2015, 10(1), 161-170.

[5] ZADRĄG, R., KNIAZIEWICZ, T. Identification of diagnostic parameter sensitivity during dynamic processes of a marine engine. The $6^{\text {th }}$ International Congress on Combustion Engines. PTNSS-2015-3507, 2015.

Tomasz Kniaziewicz, DSc., DEng. - Faculty of Mechanical and Electrical Engineering at the Polish Naval University.

e-mail:T.Kniaziewicz@amw.gdynia.pl 